\title{
THE EFFECTS OF TRAFFIC-RELATED AIR POLLUTION ON THE FLOWER MORPHOLOGY OF IRIS PUMILA - COMPARISON OF A POLLUTED CITY AREA AND THE UNPOLLUTED DELIBLATO SANDS (NATURE RESERVE)
}

\author{
VuJIĆ, V..$^{1,3}$ - AVRAMOV, S. $^{2}$ - TARASJEV, A. ${ }^{2}$ - BARIŠIĆ KLISARIĆ, N. $^{2}$ - ŽIVKOVIĆ, U. $^{2}-$ \\ MiLJKOVIĆ, D. ${ }^{2,3 *}$ \\ ${ }^{1}$ Faculty of Biology, University of Belgrade, Studentski trg 1611000 Belgrade, Serbia \\ ${ }^{2}$ Institute for Biological Research "S. Stanković", Department of Evolutionary Biology \\ University of Belgrade, Blvd Despota Stefana 142, 11000 Belgrade, Serbia \\ (phone: +3811120783 76; fax: +38111761433) \\ ${ }^{3}$ These authors equally contributed to this work and should be considered co-first authors. \\ *Corresponding author \\ e-mail:danijela.miljkovic@ibiss.bg.ac.rs,vukicavujic@yahoo.com,stevan@ibiss.bg.ac.rs, \\ tarasjev@ibiss.bg.ac.rs,dubokoiplavo@yahoo.com,uros.zivkovic@gmail.com
}

(Received $8^{\text {th }}$ Apr 2014; accepted $2^{\text {nd }}$ Aug 2014)

\begin{abstract}
The function of flowers, as the reproductive organs of plants, can be altered by changes in the size and shape of their constituent parts in traffic-related air polluted areas. The aim of this work was to compare the length, width, centroid size and shape (using a set of shape variables - partal warps) of Iris pumila standards (petals) from an urban area of Belgrade city with data from the Deliblato Sands - an unpolluted nature reserve. Differences between the areas, as well as differences in clonal variability, for length, centroid size (ANOVA $\mathrm{p}<0.001$ ) and shape variation of standards were significant (MANOVA $p$ $<0.001)$. Micro-environmental conditions induced significant diversity between flowers within a clone ( $p$ $<0.001$ ), while intra-individual variation (part effects, $\mathrm{p}>0.05$ ) was not confirmed. Decrease of standard length and centroid size in the polluted environment was detected, as well as a change in the shape of this I. pumila flower part. The standards were shorter and wider in the polluted area when compared to those in the unpolluted environment.
\end{abstract}

Keywords: urban ecology, flower shape morphology, geometric morphometrics, Iris pumila, Deliblato Sands

\section{Introduction}

Studies on the effects of urban air pollution on vegetation (Gajić et al., 2009; Bell et al., 2011), have generally demonstrated reduction in the size of plant organs in polluted environments. However, few investigations have examined the direct influence of traffic-related air pollution on plant organ shape. The complex mixture of air pollutants, characteristic for major urban roadside locations, has a potentially injurious impact on vegetation, inducing morphological and physiological changes affecting photosynthesis, which, in return, directly influence the growth and development of plants and flowering phenology (Gratani et al., 2000; Viskari et al., 2000; Honour et al., 2009; Bell et al., 2011).

As the reproductive organ of plants, flowers (i.e. their number, the size of floral parts, pollen size and viability, phenology), are one of the most convenient biomonitoring systems for the detection of environmental pollution caused by anthropogenic activity (Dubey, 1991; Neil and Wu, 2006; Syed et al., 2008). Early spring bloomers and insect- 
pollinated plants are known to be highly responsive to environmental variables. The reduction in size of plant organs in polluted areas may alter the relationship between pollinators and flowers with subsequent effects on successful pollination (Bell et al., 2011; Sun et al., 2014). Understanding the causes, mechanisms and consequences of changes in flowering phenology and morphology in urban environments has a number of important ecological implications (Neil and $\mathrm{Wu}, 2006$ ).

In this study we analyzed the impact of air pollution on the morphology of Iris pumila standards (petals) by geometric morphometrics (GM). In the last few years this method has begun to be applied as a tool in morphological analyses (Adams et al., 2004; Henderson, 2006; Adams et al., 2011; Dalayap et al., 2011). In addition to the analysis of structural dimensions (e.g. distance) based on specific landmarks (LM), contour shape analysis of organs or parts of organs, defined by semi-landmark points, are also elements of this application (Bookstein, 1997).

Specific goals of this study were:

- to define differences in the length, width, centroid size and shape of Iris pumila flower standards between an air-polluted urban area in Belgrade city and the protected natural unpolluted habitat of Deliblato Sands;

- to estimate clonal variability of the length, width, centroid size and shape of standards in the polluted and unpolluted environments.

\section{Material and methods}

\section{Locations}

We analyzed a perennial clonal plant species - Iris pumila L. (Iridaceae), which is widely distributed in the Pannonian lowlands of central and southeast Europe. Natural populations of this species are very abundant on the dune system at Deliblato Sands,

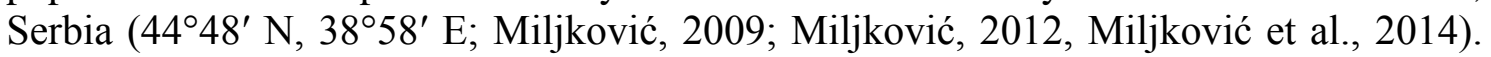
This dune system is a special nature reserve and a natural $(\mathrm{N})$, rural $(\mathrm{R})$ area according to the EoI classification of the EEA (European Environmetal Agency) and was the site of our first natural population. The second locality was the garden of the "Siniša Stanković" Institute for Biological Research, a traffic-related polluted area in Belgrade,

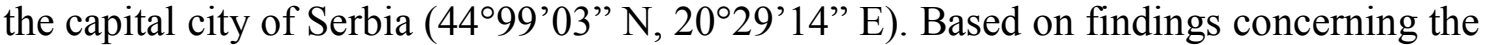
amount of pollutants in 2012, Belgrade falls in the third category regarding air pollution (highly polluted environment), with high $\mathrm{NO}_{2}\left(57.7 \mu \mathrm{g} / \mathrm{m}^{3},\right)$ and $\mathrm{PM}_{10}\left(70.8 \mu \mathrm{g} / \mathrm{m}^{3}\right)$ concentrations (Annual report on air quality in the Republic of Serbia, 2012., Ministry of Energy, Development and the Environment, CIP - Catalog. in publication of National Library of Serbia, Belgrade) (Fig. 1).

\section{Study species}

I. pumila hermaphroditic flowers consist of three floral organ sets (standard, fall, style, stamen). The three upright standards correspond to the usual flower petals and their function is to attract pollinating insects. Multiple planes of symmetry and a radially symmetrical form characterize I. pumila flowers (Tucić and Miljković, 2010; Miljković, 2012). We determined the length, width, centroid size (CS) and shape variation of standards, the corolla part of the perianth (standards and falls), in I. pumila plants using geometric morphometric tools. Standards of flowers from eleven clones in the traffic-polluted area and thirty clones from the unpolluted region were examined, a 
total of 60 blooms from each site. After dissection of the flower parts, standards were fixed with glycerol on a glass slide and images were recorded, with a ruler for calibration, on a scanner (Hewlett Packard Jet 3400C) at the resolution of $600 \mathrm{dpi}$.

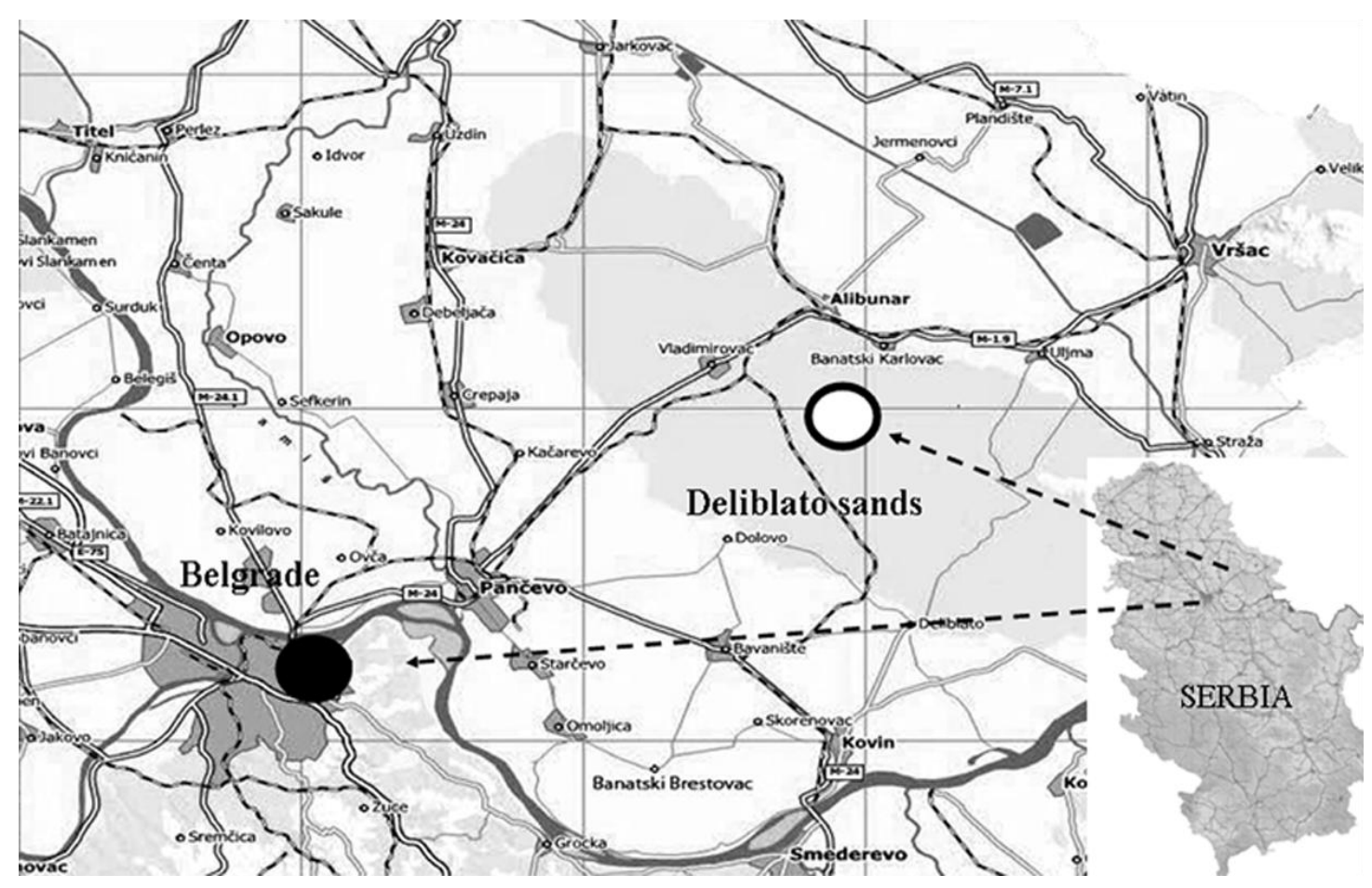

Figure 1. Locations of the analyzed populations: the unpolluted Deliblato Sands Natural Reserve (white circle) and polluted urban area in Belgrade, Serbia (black circle).

\section{Morphometric analyses}

All geometric morphometric analyses were made in the MorphoJ program (Klingenberg, 2011). This software package and a series of programs for the geometric analysis of shape (a set of TPS-thin plate spline and IMP-Integrated Morphometrics Package programs) are accessible at: http://life.bio.sunysb.edu/morph (Sheets, 2001; Klingenberg, 2011). IMP was used for digital analyses of I. pumila standards. The MakeFan6 (Sheets, 2001) was employed to create a radial fan thus ensuring uniformity in the placement of marks in all analyzed specimens. Four landmarks were defined: LM1 on the middle of the standard base, LM9 on the top of the standard and two landmarks on the ruler (LM17 and LM18) for calibration (Fig. 1). The function of semilandmarks are to facilitate the description of curves and outlines of the form and structure of an organism or one of its parts (Perez et al., 2006; Van Dongen et al., 2009). To observe the shape of the floral parts, namely, their curves, we defined semilandmarks (SML) (Fig. 2). Images of standards with the radial fan were used for positioning semi-landmarks in the tpsDig program (Rohlf, 2005). On the intersection between the radial axis and the outer curve of the standards we determined 14 SML (2-8 and 10-16, see Fig. 1). Some errors may occur during data collection and placing landmarks. To estimate errors, points were positioned at two independent times on the whole sample by the same person (V V). 


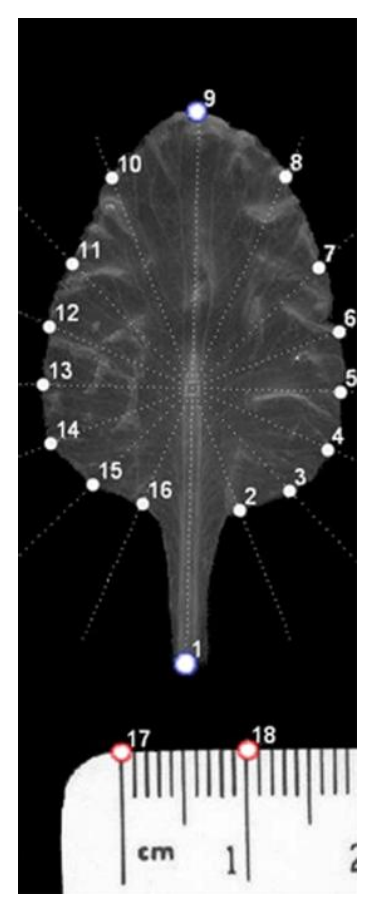

Figure 2. Digital image of a standard of Iris pumila flower. The fan, 2 landmarks and 16 semilandmarks are shown. The points 17 and 18 are positioned on the ruler for scaling.

General Procrustes Analysis (GPA) allows scaling, translation and rotation of specific points, which eliminates differences due to size, position and orientation (using Procrustes superimposition) (Dryden and Mardia, 1998; Zelditch et al., 2004). Namely, the results of GPA give geometric information about an object that is independent with respect to scaling, translation and rotation (Klingenberg and Monteiro, 2005). The Procrustes coordinates (which were obtained from GPA analyses) of each specific point provide data about the shape of the specific configuration, and differences in shape between the analyzed configurations.

\section{Statistical analysis}

Centroid size (a measure of size in geometric morphometrics) for the standard form was calculated as the square root of the sum of square distances between landmarks (Dryden and Mardia, 1998; Webster and Sheets, 2010). The CoordGen program was used to calculate shape coordinates and centroid size (CS) (Sheets, 2001).

Analysis of variance (ANOVA) with length, width and CS as the dependent variables and area and clone as independent variables was used to detect differences between the two localities, clones (nested in localities) within localities, flowers (nested in localities and clones) within clones and intra-individual variability (nested in localities and clones and flowers). Multivariate analysis of variance (MANOVA) with shape variables (partial warps, including both non-uniform and uniform shape components) as the dependent variable was used to analyze variation in standard shape (SAS, version 9.3). The amount of individual shape variation in the entire data set was estimated by Principal Component Analysis (PCA) (MorphoJ; Sheets, 2001). Canonical Variate Analysis (CVA) (MorphoJ; Sheets, 2001) was performed to assess inter-location differences in standard shape variation. 


\section{Results}

No differences existed between the two sets of samples, according to one way ANOVA, with repeated placing landmarks as a factor ( $\mathrm{p}>0.97)$. The $F$ - test (all $\mathrm{p}<$ 0.05 ) showed that mean values for the length and CS of Iris pumila standards (petals) differed between polluted and unpolluted areas, with higher values in the unpolluted than in the polluted locality ( $F=160.15, \mathrm{p}<0.001, F=40.18, \mathrm{p}<0.001$, respectively). However, the width of standards showed the reverse pattern with a higher value in the polluted than in the unpolluted area $(F=4.41, \mathrm{p}<0.040)($ Fig. 3).
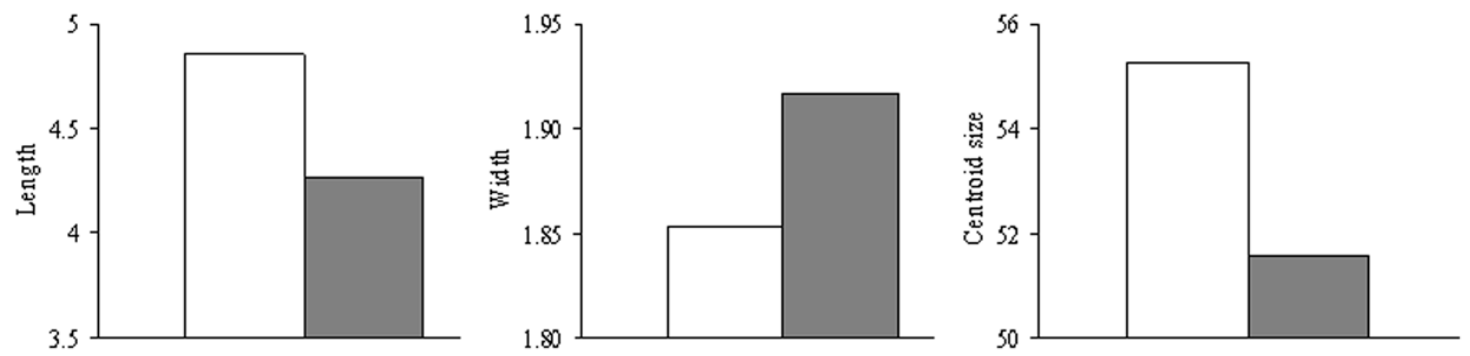

Figure 3. Mean values of length ( $\mathrm{mm})$, width $(\mathrm{mm})$ and centroid size in unpolluted (white bar) and polluted (dark bar) area.

Thus, the length and CS of standards from polluted and unpolluted habitats were markedly different (statistically significant environmental effects). Differences between clones (nested in localities) and flowers (nested in localities and clones, inter-individual components of variability) for all analyzed traits were statistically significant (ANOVA: all $\mathrm{p}<0.001$ ), while intra-individual variability of standards within a single flower was not confirmed (Table 1).

Table 1. Results of the four-way ANOVA for length, width and centroid size (CS) with locality and clones (nested in the locality) as fixed factors; flower (nested in the locality and clone) and part (nested in the locality, clone and flower), as a random factors. Df - degrees of freedom; MS- mean squares; $F$ - $F$ value.

\begin{tabular}{|c|c|c|c|c|c|c|c|}
\hline \multirow[b]{2}{*}{ Source of variation } & \multirow[b]{2}{*}{ Df } & \multicolumn{2}{|c|}{ Lenght $(\mathrm{mm})$} & \multicolumn{2}{|c|}{ Width (mm) } & \multicolumn{2}{|c|}{ Centroid size } \\
\hline & & MS & $F$ & MS & $F$ & MS & $F$ \\
\hline Locality & 1 & 29.76 & $31.57^{* * * * *}$ & 0.03 & 0.08 & 1639.99 & $8.39^{* * * * *}$ \\
\hline Clone (Locality) & 39 & 0.85 & $5.77^{* * * *}$ & 0.35 & $6.07^{* * * * *}$ & 172.97 & $6.29^{* * * * *}$ \\
\hline Flower (Locality Clone) & 41 & 0.15 & $13.22^{* * *}$ & 0.06 & $7.49^{* * * * *}$ & 27.55 & $16.47^{* * * *}$ \\
\hline Part (Locality Clone Flower) & 164 & 0.01 & 0.04 & 0.01 & 0.07 & 1.67 & 0.07 \\
\hline Error & 114 & 0.25 & & 0.10 & & 24.55 & \\
\hline
\end{tabular}

The MANOVA for Procrustes coordinates (shape variables) of standards showed significant differences between polluted and unpolluted habitats $(F=9.33, \mathrm{p}<0.001)$, as well as significant differences among the clones $(F=1.97, \mathrm{p}<0.001)$ (Table 2). Inter-individual (flower as a factor) and intra-individual differences (standard nested in 
flower as a factor) of shape were not observed $(F=1.03, \mathrm{p}<0.27 ; F=0.9, \mathrm{p}<0.99$, respectively) (Table 2).

Table 2. Results of the MANOVA for shape variables-the PC scores (Procrustes coordinates), with locality and clones (nested in locality) as fixed factors; flower (nested in locality and clone) and part (nested in locality, clone and flower) as a random factors. WL - Wilks' Lambda value; Den $D f$ - denominator's degrees of freedom; Num $D f$-numerator's degrees of freedom. $F$ - $F$ value.

\begin{tabular}{l|c|c|c|l}
\hline Source of variation & WL Value & Num Df & Den Df & $F$ \\
\hline Locality & 0.22 & 32 & 83 & $9.33^{* * * *}$ \\
Clone (Locality) & 0.00 & 1248 & 2274.2 & $1.67^{* * * *}$ \\
Flower (Locality Clone) & 0.00 & 1312 & 2324.4 & $1.03^{\text {ns }}$ \\
Part (Locality Clone Flower) & 0.00 & 5248 & 3015.2 & $0.90^{\text {ns }}$ \\
\hline
\end{tabular}

ns $=$ non significant, ${ }^{*} \mathrm{P}<0.05,{ }^{* *} \mathrm{P}<0.01,{ }^{* * * *} \mathrm{P}<0.001,{ }^{* * * * *} \mathrm{P}<0.0001$.

To explore the distribution of total variation for standards from polluted and unpolluted habitats PCA was performed. The first two principal components, PC1 and PC2 explained $86.22 \%$ of the total variance (PC1 67.03\%, PC2 19.19\%). The vector position of all points and the thin-plate spline deformation grids along the first and the second axis illustrated shape differences in standards between polluted and unpolluted habitats (Fig. 4). Canonical variate analysis (CVA) indicated a significant difference in standard shape between polluted and unpolluted habitats. The deformation grids along the first $\mathrm{CV}$ axis showed that standards from the polluted habitat were broader and shorter than those from the unpolluted habitat (Fig. 5).
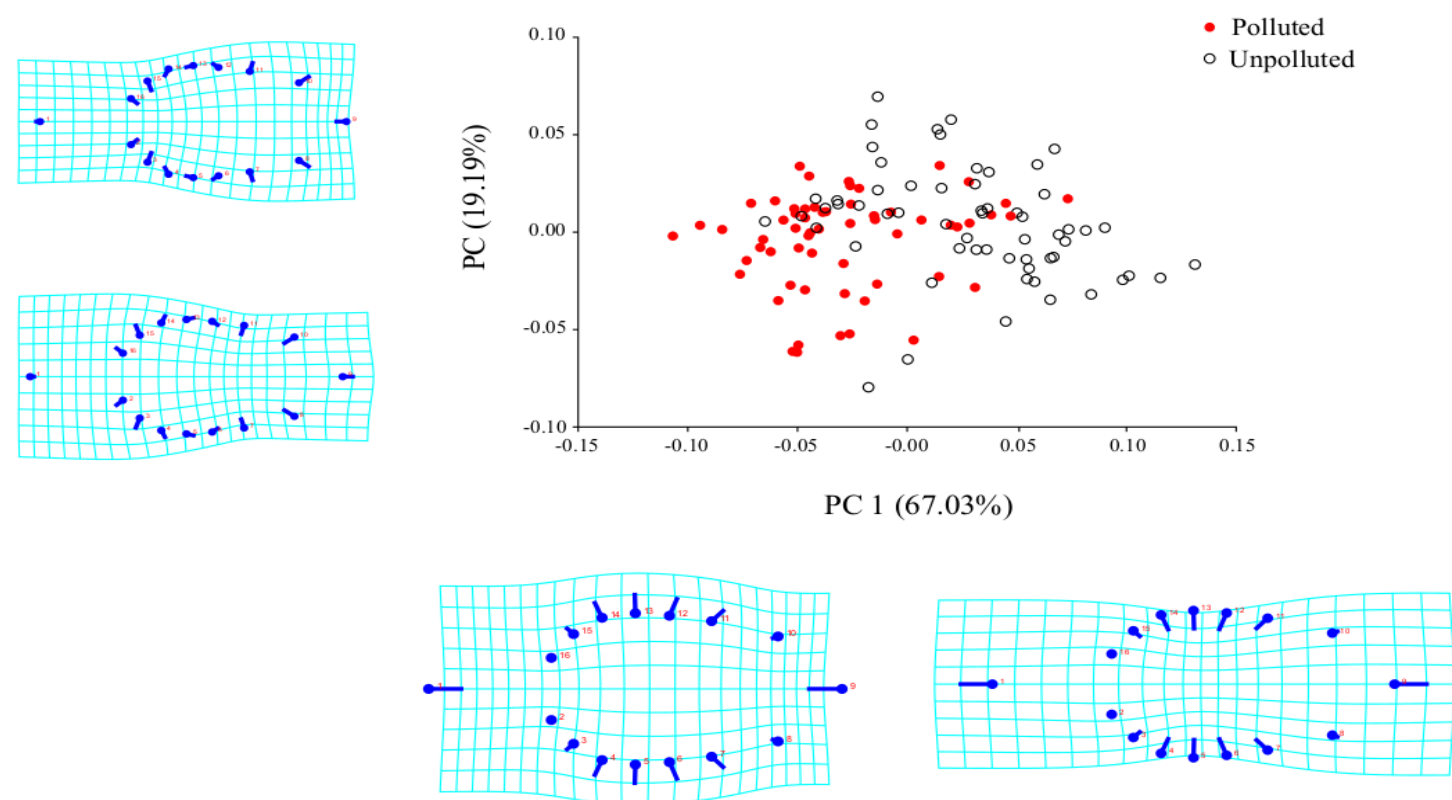

Figure 4. Graphical visualization of all shape variation in a sample of principal component analysis. The patterns of shape change are explained by direction of vectors and thin-plate spine deformation grids (white dots unpolluted area, dark dots polluted area). 

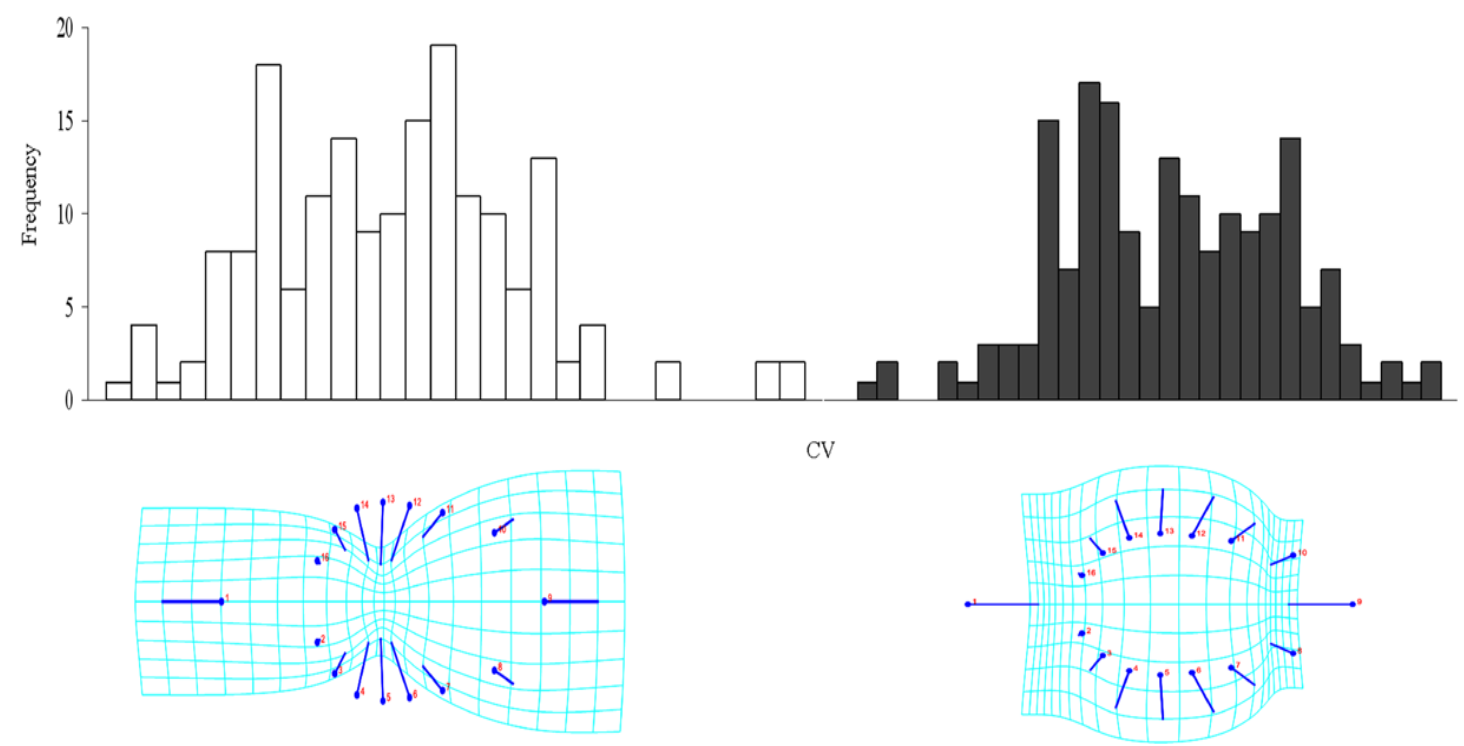

CV

Figure 5. The degree of differentiation between standards from polluted and unpolluted habitat by the Canonical Variate Analysis (white bars unpolluted area, dark bars polluted area). The thin-plate spline deformation grids along the first axis represented standard shape changes.

\section{Discussion}

In the last two decades, evolutionary ecology research on I. pumila (a threatened species in Serbia) has confirmed that various environmental conditions can modify its morphological, anatomical and eco-physiological traits (Tarasjev et al., 2012), the stability of flower development (Miljković, 2012) and trace element accumulation (Miljković et al., 2014).

The impact of traffic-related air pollution as a stress factor on ecosystems and biodiversity in urban areas depends on the types of organisms exposed, the specifics of pollutants and their complex influence on the ecosystem (Driscoll et al., 2001). Ecophysiological parameters of plants show significant responses to the quality of urban surroundings, such as alterations in morpho-anatomical traits, although some properties are less investigated in this type of research (Balasooriya et al., 2009; Gajić et al., 2009; Miljković et al., 2014).

In this study we used geometric morphometrics software as a tool for morphometric analysis in quantitative evolutionary research on biological forms (Henderson, 2006). We compared some traditional linear data, i.e. the length and the width of an I. pumila flower part, the standard (petal), by geometric morphometric analysis. Thus, we obtained centroid size (geometric measure of size) as a single multidimensional trait together with shape (using the observed Procrustes distance), which we used in multivariate analysis. The pattern of results was the same for both applied methods. Small changes in the form of morphological units, which cannot be determined by traditional morphometric methods, can be perceived with GM owing to its great statistical sensitivity (Klingenberg, 2002). Even relatively subtle changes in the shape of parts of organisms can be significant in a biological context (Klingenberg, 2013).

Similar analyses of flower shape based on variable composed sets of several linear measurements have been applied earlier (Zelditch et al., 2004; Gomez et al., 2008). 
Recent findings confirm reduction of plant growth as a consequence of pollution stress (Gupta and Iqbal, 2005; Maruthi Sridhar et al., 2005, 2007; Syed et al., 2008). In this study, we observed statistically significant differences between polluted and unpolluted areas in Iris flower parts. Namely, the length, width, CS (Table 1) and shape (Table 2) of I. pumila standards responded to environmental factors (localities $\mathrm{p}<0.001$ ). Variability of clones within localities was confirmed too (Table 1 and Table 2). In the traffic polluted area values for standard length and CS were lower than in the unpolluted environment (Fig. 3). Thus, standards from the polluted habitat were broader and shorter than those from the unpolluted habitat (Fig. 5).

The results of Syed and colleagues (2008) indicated injuries to Cassia glauca Lamk. flower parts in an air-polluted area, where the sizes of sepals, petals, stamens and carpel were decreased. Similar results were observed for Calendula (D. regia, P. innerme) and Cassia siamea. In comparison to a low pollution area the patterns of size reduction for sepals and petals were different, i.e. sepal length and width decreased more than for petals. Pollution also disturbed plant metabolism and photosynthesis, influenced plant growth, flower morphology and reproductive biology (Syed et al., 2008).

The concentration of pollutants in contaminated environments and their absorption in tissue affects plant growth, processes of cell division and tissue elongation, which may influence the size and shape of the plant parts. For example, exploration of the impact of heavy metals in maize roots confirmed that lead $(\mathrm{Pb})$ affects cell elongation much more strongly than nickel (Ni) (Kozhevnikova et al., 2009 and references therein). Concentrations of $\mathrm{Pb}$ and $\mathrm{Ni}$ in I. pumila leaves were found to be about six times higher in an urban area than in an unpolluted nature reserves (Miljković et al., 2014). This may be the reason for reduction in the length and size of standards in our analyzed flowers. The phenotype of flowers, e.g. size and color, results from adaptation to their pollinators which determines their reproductive success (Harder and Johnson, 2009; Parachnowitsch and Kessler, 2010). The impact of pollutants on the phenotypic variability of flower parts may therefore affect reproductive success and its adaptive value, influencing directly the relationship between flowers and pollinators. The importance of particular parts of flowers for attracting pollinators is species-specific. Namely, experimental removal of standards from Iris atrofucosa did not reduce the frequency of pollinator visits, while the whole flower of Iris hermona gave a selective advantage enabling more frequent visits of pollinators than flowers with removed parts (Sapir, 2004). Therefore, in addition to the direct harmful influence on plant growth and survival, heavy metal toxicity can have ecological and evolutionary effects (Elobeid and Polle, 2012).

Alterations in plants in urban ecosystems will lead to changes in plant traits and their interactions in novel environments as possible new selective forces (Pickett et al., 2001; $\mathrm{Wu}$ and David, 2002; Neil and Wu, 2006). The statistically significant effect of clones, as a factor in the analyzed traits of standard size and shape (Table 1 and Table 2) indicates the possible existence of genetic variability within these traits, which is a prerequisite for evolution under the influence of natural selection.

The basic advantage and the benefit of using geometric morphometrics as a simple and inexpensive tool for biological morphological analyses is not only useful for biomonitoring and impact assessment of urban habitats (especially air pollution), but also for estimating their effects on plant evolution. 
Acknowledgements. This work was funded by the Ministry of Education, Science and Technological Development of Serbia (project OI 173025 "Evolution in heterogeneous environments: mechanisms of adaptation, biomonitoring and conservation of biodiversity"). The funding agency was not involved in the study design, collection, analysis and interpretation of the data, or in writing and the decision to publish the results.

\section{REFERENCES}

[1] Adams, D.C., Cardini, A., Monteiro, L.R., O'Higgins, P., Rohlf, F.J. (2011): Morphometrics and phylogenetics: principal components of shape from cranial modules are neither appropriate nor effective cladistic characters. - J. Hum. Evol. 60: 240-243.

[2] Adams, D.C., Rohlf, F.J., Slice, D.E. (2004): Geometric Morphometrics: Ten years of progress following the revolution. - Ital. J. Zool. 71: 5-16.

[3] Balasooriyaa, B.L.W., Samsona, R., Mbikwaa, F., Vitharanac, U.W.A., Boeckxb, P., Van Meirvennec, M. (2009): Biomonitoring of urban habitat quality by anatomical and chemical leaf characteristics. - Environ. Exper. Bot. 65: 386-394.

[4] Bell, J.N.B., Honour, S.L., Power, S.A. (2011): Effects of vehicle exhaust emissions on urban wild plant species. - Environ. Pollut. 159: 1984-1990.

[5] Bookstein, F.L. (1997): Morphometric tools for landmark data: geometry and biology. Cambridge University Press, Cambridge.

[6] Dalayap, R.M., Torres, M.A.J., Demayo, C.G. (2011): Landmark and Outline Methods in Describing Petal, Sepal and Labellum Shapes of the Flower of Mokara Orchid Varieties. Int. J. Agr. Biol. 13: 652-658.

[7] Driscoll, C.T., Lawrence, G.B., Bulger, A.J., Butler, T.J., Cronan, C.S., Eagar, C., Lambert, K.F., Likens, G.E., Stoddard, J.L., Weathers, K.C. (2001): Acidic Deposition in the Northeastern United States: sources and inputs, ecosystem effects, and management strategies. - BioScience 51: 180-198.

[8] Dryden, I.L., Mardia, K.V. (1998): Statistical Shape Analysis. - John Wiley and Sons, New York.

[9] Dubey, P.S. (1991): Biomonitoring the environment, Theory practice and problems. - J. Environ. Biol. 19: 233-241.

[10] Elobeid, M., Polle, A. (2012): Interference of heavy metal toxicity with auxin physiology. - Metal Toxicity in Plants: Perception, Signaling and Remediation 249-259.

[11] Gajić, G., Mitrović, M., Pavlović, P., Stevanović, B., Djurdjević, L., Kostić, O. (2009): An assessment of the tolerance of Ligustrum ovalifolium Hassk. to traffic-generated $\mathrm{Pb}$ using physiological and biochemical markers. - Ecotoxicol. Environ. Saf. 72: 1090-1101.

[12] Gómez, J.M., Bosch, J., Perfectti, F., Fernández, J.D., Abdelaziz, M., Camacho, J.P.M. (2008): Spatial variation in selection on corolla shape in a generalist plant is promoted by the preference patterns of its local pollinators. - Proc. R. Soc. B 275: 2241-2249.

[13] Gratani, L., Crescente, M.F., Petruzzi, M. (2000): Relationship between leaf life-span and photosynthetic activity of Quercus ilex in polluted urban areas (Rome). - Environ. Pollut. 110: 19-28.

[14] Gupta, M.C., Iqbal, M. (2005): Ontogenetic histological changes in the wood of mango (Mangifera indica L.) exposed to coal-smoke pollution. - Environ. Exper. Bot. 54: 248255.

[15] Harder, L.D., Johnson, S.D. (2009): Darwin's beautiful contrivances: evolutionary and functional evidence for floral adaptation. - New Phytol. 183: 530-545.

[16] Henderson, A. (2006): Traditional morphometrics in plant systematics and its role in palm systematics. - Bot. J. Linn. Soc. 151: 103-111.

[17] Honour, S.L., Bell, J.N.B., Ashenden, T.W., Cape, J.N., Power, S.A. (2009): Responses of herbaceous plants to urban air pollution: effects on growth, phenology and leaf surface characteristics. - Environ. Pollut. 157: 1279-1286. 
[18] Klingenberg, C.P. (2002): Morphometrics and the role of the phenotype in studies of the evolution of developmental mechanisms. - Gene 287: 3-10.

[19] Klingenberg, C.P. (2011): MorphoJ: an integrated software package for geometric morphometrics. - Mol. Ecol. Resour. 11: 353-357.

[20] Klingenberg, C.P. (2013): Visualizations in geometric morphometrics: how to read and how to make graphs showing shape changes. - Hystrix 24: 15-24.

[21] Klingenberg, C.P., Monteiro, L. R. (2005): Distances and directions in multidimensional shape spaces: implications for morphometric applications. - Syst. Biol. 54: 678-688.

[22] Kozhevnikova, A.D., Seregin, I.V., Bystrova, E.I., Belyaeva, A.I., Kataeva, M.N., Ivanov, V.B. (2009): The effects of lead, nickel, and strontium nitrates on cell division and elongation in maize roots. - Russ. J. Plant Physiol. 56: 242-250.

[23] Miljković, D. (2009): Effects of abiotic stress on developmental stability and morphological variability of Iris pumila in natural and experimental populations. $\mathrm{PhD}$ Thesis. Institute for Biological Research "Siniša Stanković", University of Belgrade, Serbia. Available at 10.2298/BG20090918MILJKOVIC.

[24] Miljković, D. (2012): Developmental stability of Iris pumila flower traits: A common garden experiment. - Arch. Biol. Sci. 64: 123-133.

[25] Miljković, D., Avramov, S., Vujić, V., Rubinjoni, L., Barišić Klisarić, N., Živković, U., Tarasjev, A. (2014): Lead and nickel accumulation in Iris pumila: consideration of its usefulness as a potential bioindicator in the natural protected area of Deliblato sands, Serbia. - Arch. Biol. Sci. 66 : 331-336.

[26] Neil, K., Wu, J. (2006): Effects of urbanization on plant flowering phenology: A review. Urban Ecosyst. 9: 243-257.

[27] Parachnowitsch, A.L., Kessler, A. (2010): Pollinators exert natural selection on flower size and floral display in Penstemon digitalis. - New Phytol. 188: 393-402.

[28] Perez, S.I., Bernal, V., Gonzalez, P.N. (2006): Differences between sliding semi-landmark methods in geometric morphometrics, with an application to human craniofacial and dental variation. - J. Anat. 208: 769-784.

[29] Pickett, S.T.A., Cadenasso, M.L., Grove, J.M., Nilon, C.H., Pouyat, R.V., Zipperer, W.C., Costanza, R. (2001): Ecological, Physical, and Socioeconomic Components of Metropolitan Areas. - Annu. Rev. Ecol. Syst. 32: 127-57.

[30] Rohlf, F.J. (2005): TpsDig, digitize landmarks and outlines, version 2.04. - Department of Ecology and Evolution, State University of New York at Stony Brook, New York. (http://life.bio.sunysb.edu/morph/)

[31] Sapir, Y. (2004): Pollination ecology of Oncocyclus irises. PhD Thesis. Department of Evolution, Systematics and Ecology, Hebrew University of Jerusalem, Israel.

[32] SAS Institute Inc. (2011): SAS/STAT User's Guide, version 9.1.3, Cary, N.C., SAS Institute Inc.

[33] Sheets, H.D. (2001): IMP, integrated morphometric package: http://www3.canisius.edu/ sheets/morphsoft.html

[34] Sridhar, B.B., Diehl, S.V., Han, F.X., Monts, D.L., Su, Y. (2005): Anatomical changes due to uptake and accumulation of $\mathrm{Zn}$ and $\mathrm{Cd}$ in Indian mustard (Brassica juncea). - Environ. Exper. Bot. 54: 131-141.

[35] Sridhar, B.B.M., Han, F.X., Diehl, S.V., Monts, D.L., Su, Y. (2007): Effects of Zn and Cd accumulation on structural and physiological characteristics of barley plants. - Braz. J. Plant Physiol. 19: 15-22.

[36] Sun, M., Gross, K., Schiestl, F.P. (2014): Floral adaptation to local pollinator guilds in a terrestrial orchid. - Ann. Bot. 113: 289-300.

[37] Syed, K., Tiwari, S., Sikka1, J., Panwar, K. (2008): Impact of air pollution on floral morphology and characteristics of Cassia glauca Lamk. In Indore (India). - J. Environ. Res. Develop. 3: 91-96. 
[38] Tarasjev, A., Avramov, S., Miljković, D. (2012): Evolutionary biology studies on the Iris pumila clonal plant: Advantages of a good model system, main findings and directions for further research. - Arch. Biol. Sci. 64: 159-174.

[39] Tucić, B., Miljković, D. (2010): Fluctuating asymmetry of floral organ traits in natural populations of Iris pumila from contrasting light habitats. - Plant Spec. Biol. 25: 173184.

[40] Van Dongen, S., Cornille, R., Lens, L. (2009): Sex and asymmetry in humans: what is the role of developmental instability? - J. Evolut. Biol. 22: 612-622.

[41] Viskari, E.L., Holopainen, T., Kärenlampi, L. (2000): Responses of spruce seedlings (Picea abies) to exhaust gas under laboratory conditions-II ultrastructural changes and stomatal behaviour. - Environ. Pollut. 107: 99-107.

[42] Webster, M.A.R.K., Sheets, H.D. (2010): A practical introduction to landmark-based geometric morphometrics. - Quantitative Methods in Paleobiology Paleontological Society Papers 16: 163-188.

[43] Wu, J., David, J. L. (2002): A spatially explicit hierarchical approach to modeling complex ecological systems: theory and applications. - Ecol. Model. 153: 7-26.

[44] Zelditch, M.L., Swiderski, D.L., Sheets, H.D., Fink, W.L. (2004): Geometric morphometrics for biologists: A primer. - Elsevier Academic Press, San Diego. 